American Journal of Applied Sciences 8 (5): 413-419, 2011

ISSN 1546-9239

(C) 2010 Science Publications

\title{
Prophylactic Effects of Melatonin on Sodium Valproate-Induced Neural Tube Defects and Skeletal Malformations in Rat Embryos
}

\author{
${ }^{1}$ Mahmood Khaksary Mahabady, ${ }^{2}$ Hossien Najafzadeh Varzi, \\ ${ }^{1}$ Reza Ranjbar and ${ }^{3}$ Omolbanin Rahgazar \\ ${ }^{1}$ Department of Pharmacology, \\ ${ }^{2}$ Department of Anatomy and Embryology, \\ School of Veterinary Medicine, \\ Shahid Chamran University, Ahvaz, Iran \\ ${ }^{3}$ Department of Anatomy and Embryology School of Veterinary Medicine, \\ Shahid Chamran University, Ahvaz, Iran
}

\begin{abstract}
Problem statement: Some reports showed the teratogenic effects of sodium valproate can be prevented by application of antioxidant drugs and stimulation of the maternal immune system. Therefore, in this study, the prophylactic effect of melatonin on teratogenic effects of sodium valproate was compared. Approach: This study was performed on 31 pregnant rats that were divided into five groups. Control group received normal saline and test groups received sodium valproate $(300 \mathrm{mg}$ $\left.\mathrm{kg}^{-1}\right)$, sodium valproate $\left(300 \mathrm{mg} \mathrm{kg}^{-1}\right)$ plus melatonin $\left(5 \mathrm{mg} \mathrm{kg}^{-1}\right)$ and sodium valproate $\left(300 \mathrm{mg} \mathrm{kg}^{-1}\right)$ plus melatonin $\left(10 \mathrm{mg} \mathrm{kg}^{-1}\right)$ and melatonin $\left(10 \mathrm{mg} \mathrm{kg}^{-1}\right)$, intraperitonealy at 8-9th days of gestation, respectively. Fetuses were collected at 20th day of gestation and after determination of weight and length; they were stained by Alizarin red-Alcian blue method. Results: Cleft palate, spina bifida and exencephaly incidence were $17.70,20$ and $20 \%$ in fetuses of rats that received only sodium valproate. Cleft palate, spina bifida and exencephaly incidence were $4.16,8.33$ and $8.33 \%$ range in group which received sodium valproate plus melatonin $\left(5 \mathrm{mg} \mathrm{kg}^{-1}\right)$, respectively. However, Cleft palate, spina bifida and excencaphaly incidence were 4/76, 0 and $0 \%$ in group which received sodium valproate plus melatonin $\left(10 \mathrm{mg} \mathrm{kg}^{-1}\right)$, respectively. The mean of weight and length of animals' fetuses that received melatonin were significantly greater than those received only sodium valproate. Conclusion: It is concluded that melatonin with dose of $10 \mathrm{mg} \mathrm{kg}^{-1}$ had significantly more prophylactic effect than melatonin with dose of $5 \mathrm{mg} \mathrm{kg}^{-1}$ on incidence of sodium valproate-induced skeletal malformations.
\end{abstract}

Key words: Melatonin, cleft palate, valproic acid, Reactive Oxygen Species (ROS), skeletal malformations, antioxidant activity, oxidative stress

\section{INTRODUCTION}

Valproate is often prescribed as a long-term therapeutic mood-stabilizing agent for individuals with bipolar disorder (Wang et al., 2003). Valproate (Valproic acid-VAP) is a major anti-epileptic drug with a broad spectrum of anti-epileptic activity. It has been the drug of choice in the treatment of most forms of primary generalized epilepsies and is also efficient against partial seizures (Rowan et al., 1997). Valproic acid, a commonly used antiepileptic agent, is associated with a $1-2 \%$ incidence of neural tube defects when taken during pregnancy; however, the molecular mechanism by which this occurs has not been elucidated (Defoort and Winn, 2006). As many as $10 \%$ of the 12000 infants that are exposed to anti-epileptic drugs during pregnancy every year show malformations (Finnell, 1991;
Lindhout and Omtzigt, 1992). Use of VPA during the first trimester of pregnancy significantly increases the risk for spina bifida as well as other malformations such as heart defects, limb abnormalities, cleft palate and craniofacial abnormalities (Finnell, 1991; Lammer et al., 1987). Together these abnormalities constitute the fetal valproate syndrome (Clayton-Smith and Donnai, 1995). Many other structurally unrelated anti-epileptic and antimanic drugs, such as lithium, barbiturates and carbamazepine, are also teratogenic when used during pregnancy (Finnell, 1991, Koch et al., 1992).

Several studies suggest that valproic acid exposure leads to an increase in Reactive Oxygen Species (ROS). Long-term use of antiepileptic drugs has been shown to increase free radical formation and cause oxidative damage within neuronal cells (Maertens et al., 1995). The metabolism of valproate may trigger oxygen

Corresponding Author: M. Khaksary Mahabady, Department of Anatomy and Embryology, School of Veterinary Medicine, Shahid Chamran University, Ahvaz, Iran Tel: +986113330073/+989131619252 Fax: +986113360807 
dependent tissue injury and elevate the free radicals in the body (Cengiz et al., 2000).

Non-specific stimulation of the maternal immune system in mice during the peri-conception period appears to have a broad spectrum efficacy for reducing teratogen induced birth defects from a variety of sources including chemical agents, $\mathrm{x}$-rays and diabetes mellitus (Nomura et al., 1990; Holladay et al., 2000; Punareewattana and Holladay, 2004). Maternal immune stimulation reduced or blocked digit and limb defects (Prater et al., 2004), tail malformation, cleft palate (Sharova et al., 2002) cranial defects (Hrubec et al., 2006) and neural tube defects (Turchinsky et al., 1997; Punareewattana and Holladay, 2004). The operating mechanisms by which such immune stimulation reduces fetal dysmorphogenesis are unknown; however, the collective literature suggests that immunoregulary cytokines of maternal or placental origin may be effector molecules that normalize dysregulated apoptosis or timing of cell proliferation in the fetus (Punareewattana and Holladay, 2004; Sharova et al., 2000). Stimulation of maternal immune system or antioxidant drugs can decrease or prevent drug- induced embryonic abnormalities (Holladay et al., 2002; Prater et al., 2004). For example, macrophage activation decreases incidence of cleft palate and digital and tail anomalies in fetuses of mice that received urethane and methylnitrous urea (Holladay et al., 2000). Interferon gamma reduces urethane-induced cleft palate and granulocyte-colony stimulating factor decreases cyclophosphamide -induced distal limb abnormalities in mice (Syska et al., 2004).

Melatonin or N-Acetyl-5-methoxytryptamine, the main secretary product of pineal gland, participates in many physiological functions due to its efficacy as a free radical scavenger and indirect antioxidant (Tan et al., 2002; Reiter and Tan, 2003). Because of its small size and lipophilicity, melatonin crosses biological membrane easily, thus, reaching all compartments of the cell. Melatonin has also been shown to be an efficient protector of DNA, protein and lipids in cellular membrane (Cuzzocrea and Reiter, 2002) as well as antagonist of a number of endogenous and exogenous free radicals attach or during cellular processes (Zhang et al., 1998).

Melatonin has been shown to have antiepileptic activity in animal studies using different seizure models (Mevissen and Ebert, 1998; Srivastava et al., 2002). A few mechanisms for anticonvulsant activity of melatonin have been suggested. It exerts neuroprotection due to its antioxidant, antiexcitotoxic and free scavenging properties within the central nervous system (Espinar et al., 2000). It has also been demonstrated to be safe in humans even in high pharmacological doses (Reiter et al., 1994).

In present study, the preventive effect of melatonin on VAP-induced neural tube defects and skeletal malformations in rats was compared.

\section{MATERIALS AND METHODS}

Drugs: Sodium valproate (Sigma, USA) and melatonin (Sigma, USA) purchased from commercial sources.

Animals: Male and female healthy rat of Wistar strain, 3-4 month old, weighing 200-250g were purchased (Razi Institute, Karadje, Iran) and housed individually (males) or at 10 per polycarbonate cage (female) for a 2-week acclimatization period. Rats were fed ad libitum standard laboratory pellet (Pars khurakdam, Shushtar, Iran.) and tap water. A 12-h light: 12-h dark cycle was maintained. Room temperature was at $23 \pm 2^{\circ} \mathrm{C}$ with a relative humidity of $45-55 \%$.

Female rats were mated overnight with males. The vaginal plug was assumed as first day of gestation (GD1). Pregnant rats $(n=31)$ were randomly divided into five groups ( 25 pregnant rats in treatment groups, 6 pregnant rats in control group).

Exprimental protocol: Control group received normal saline, the test groups received sodium valproate (300 $\mathrm{mg} \mathrm{kg}$ ) (Menegola et al., 1998), sodium valproate (300 $\mathrm{mg} \mathrm{kg}^{-1}$ ) plus melatonin $\left(5 \mathrm{mg} \mathrm{kg}^{-1}\right)$ (Konar et al., 2007), sodium valproate $\left(300 \mathrm{mg} \mathrm{kg}^{-1}\right)$ plus melatonin $\left(10 \mathrm{mg} \mathrm{kg}^{-1}\right)$ (Konar et al., 2007) and melatonin $(10 \mathrm{mg}$ $\mathrm{kg}^{-1}$ ) (Konar et al., 2007) intraperitonealy, respectively.

The animals were sacrificed by cervical dislocation 20th day of gestation and fetuses were collected and numbered, then their weight and length (crown- rump length) were measured. Fetuses were stained by Alizarin red-Alcian blue method (Kimmel and Trammekl, 1981) and examined by stereomicroscope for neural tube defects and skeletal malformations. The incidence of neural tube defects and skeletal malformations were determined.

Statistical analysis: Statistical significance between groups was determined using SPSS program and comparisons were made by one way Analysis Of Variance (ANOVA) and Chi-square test. The minimum level of significance was $p<0.05$.

\section{RESULTS}

Fourty-seven fetuses were obtained from six rats of control group. In control group, palatal closures of 
fetuses were normal on gestational day 20 (i.e. palatal shelves had grown vertically on the sides of the tongue, then horizontally to meet and fuse) (Fig. 1, 2A) and no macroscopic anomalies were observe in them. VAP induced cleft palate (Fig. 1, 2B), spina bifida (Fig. 3 B) and exencephaly (Fig. 4) at 17.70, 20 and 20\% incidence, respectively. Sodium valproate plus melatonin $\left(5 \mathrm{mg} \mathrm{kg}^{-1}\right)$ significantly reduced incidence of cleft palate, spina bifida and exencephaly to $4.16 \%$, 8.33 and $8.33 \%$ range but sodium valproate plus melatonin $\left(10 \mathrm{mg} \mathrm{kg}^{-1}\right)$ significantly reduced incidence of cleft palate, spina bifida and exencaphaly to $4.76 \%$, 0 and $0 \%$ range, respectively. Incidence of omphalocele and fusion of two or more sternebrae, absence of sternebrae and malpositioning of two halves of the sternebrae (Fig. 5) in group which received sodium valproate were 11.1 and $15.5 \%$, respectively.

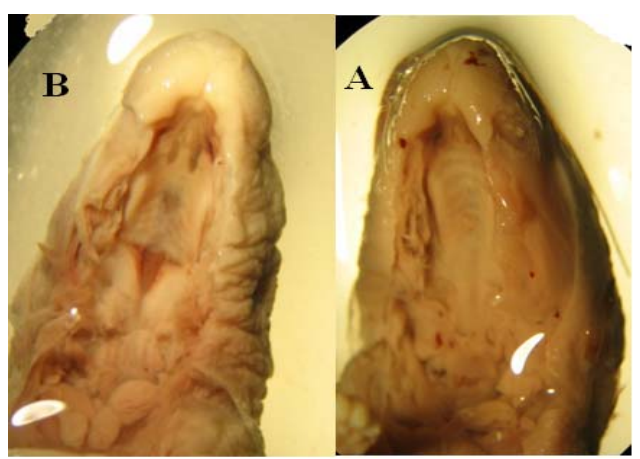

Fig. 1: Razor blade sections of rat fetuses of GD 20. (A) Control skeleton. Note the cleft palate due to palatal shelf hypoplasia (B) in the treated case (300 mg kg ${ }^{-1}$ of VAP, treated on GD 8,9)

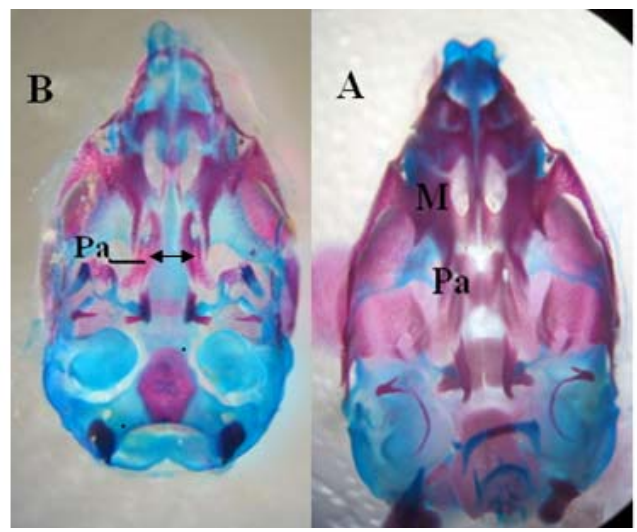

Fig. 2: Ventral view of skull of rat fetuses of GD 20, stained with alizarin red S- alcian blue. (A) Normal palatine bone (B) Cleft palate induced by VAP (arrow). M: maxilla; Pa: palatine

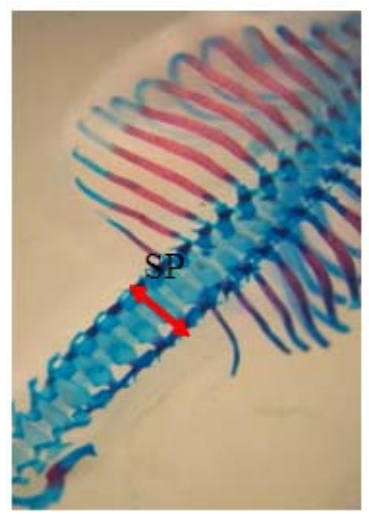

(B)

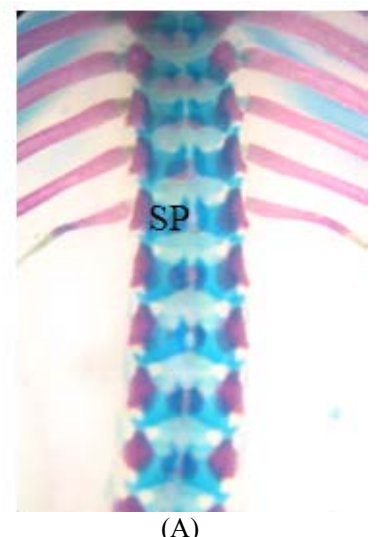

(A)
Fig. 3: Dorsal view of vertebral column of rat fetuses of GD 20, stained with alizarin red S- alcian blue. (A) Normal (B) Spina bifida (arrow) induced by VAP. SP; spinous process

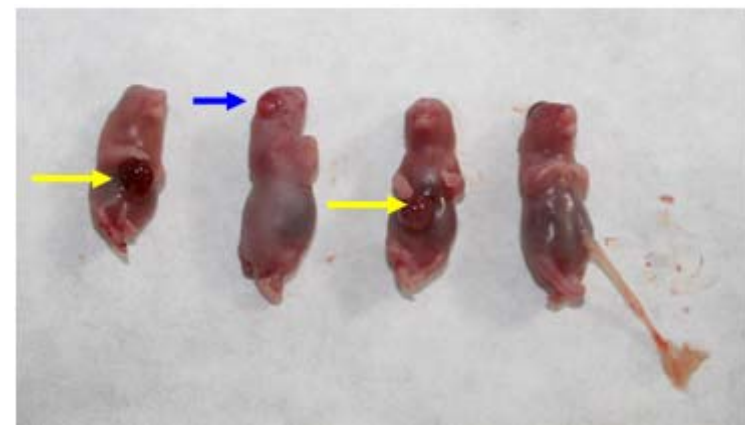

Fig. 4: Exencephaly (blue arrow) and omphalocele (yellow arrow) in experimental group treated with $300 \mathrm{mg} \mathrm{kg}^{-1}$ of VAP on GD 8-9

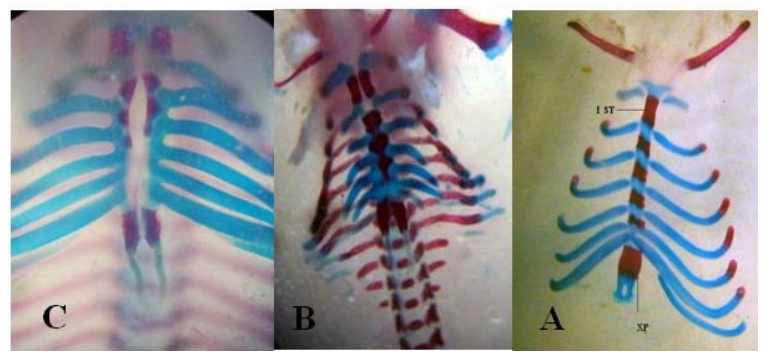

Fig. 5: Sterna of fetuses of GD 20, stained with alizarin red S--alcian blue. (A) Control. The chest wall together with the sternum and costal elements are dissected out and shown here. (B and $\mathrm{C}$ ) Experimental group treated with $300 \mathrm{mg}$ $\mathrm{kg}^{-1}$ of VAP on GD 8-9. Observe fusion of sternebra (B, C), hemisternebra (C) and unusal shape of xiphoid process 
Am. J. Applied Sci., 8 (5): 413-419, 2011

Table 1: Incidence of anomalies in rat fetuses of groups

\begin{tabular}{|c|c|c|c|c|c|c|c|c|c|c|c|}
\hline \multirow[b]{2}{*}{ Groups } & \multirow[b]{2}{*}{$\begin{array}{l}\text { No. of } \\
\text { litters }\end{array}$} & \multirow[b]{2}{*}{ Implantations } & \multirow[b]{2}{*}{$\begin{array}{l}\text { Resorbed } \\
\text { fetuses }\end{array}$} & \multirow[b]{2}{*}{$\begin{array}{l}\text { Live } \\
\text { fetuses }\end{array}$} & \multirow{2}{*}{$\begin{array}{l}\begin{array}{l}\text { Fetal } \\
\text { length } \\
(\text { mea } n \pm\end{array} \\
\text { SEM) }\end{array}$} & \multirow{2}{*}{$\begin{array}{l}\text { Fetal } \\
\text { weight } \\
\text { (g): (mean } \\
\pm \text { SEM) }\end{array}$} & \multicolumn{5}{|c|}{ No . of fetuses with malformations } \\
\hline & & & & & & & Omphalocele & $\begin{array}{l}\text { Cleft } \\
\text { palate }\end{array}$ & $\begin{array}{l}\text { Spina } \\
\text { bifida }\end{array}$ & $\begin{array}{l}\text { Stennal } \\
\text { malformations }\end{array}$ & Exencephaly \\
\hline Control & 6 & 49 & $2(4.08)$ & 47 & $37.48 \pm 0.38$ & $4.73 \pm 0.09$ & 0 & 0 & 0 & 0 & 0 \\
\hline VAP & 6 & 51 & $6(11.76)$ & 45 & $26.38 \pm 0.48^{*}$ & $2.10 \pm 0.09^{*}$ & $5(11.1)$ & $8(17.7)$ & $9(20)$ & $7(15.5)$ & $9(20)$ \\
\hline $\begin{array}{l}\mathrm{VAP}+\mathrm{Mel} \\
\left(5 \mathrm{mg} \mathrm{kg}^{-1}\right)\end{array}$ & 7 & 52 & $4(7.69)$ & 48 & $31.84 \pm 0.88 * *$ & $3.44 \pm 0.21 * *$ & $4(8.3)$ & $2(4.1)$ & $4(8.3)$ & $4(8.3)$ & $4(8.3)$ \\
\hline $\begin{array}{l}\text { VAP+Mel } \\
\left(10 \mathrm{mg} \mathrm{kg}^{-1}\right)\end{array}$ & 6 & 44 & $2(4.54)$ & 42 & $35.39 \pm 0.3 \#$ & $4.06 \pm 0.09 \#$ & 0 & $2(4.7)$ & 0 & $3(7.1)$ & 0 \\
\hline Melatonin & 6 & 43 & $2(4.65)$ & 41 & $35.59 \pm 0.85$ & $4.39 \pm 0.16$ & 0 & 0 & 0 & 0 & 0 \\
\hline
\end{tabular}

Numerals in parantheses are percentages, ${ }^{*}$ : Significant difference when compared with other groups $(\mathrm{p}<0.05)$,**: Significant difference when compared with control,VAP and melatonin groups $(\mathrm{P}<0.05)$,\#: Significant difference when compared with VAP, melatonin and VAP+ melatonin $\left(5 \mathrm{mg} \mathrm{kg}^{-1}\right)$ groups $(\mathrm{p}<0.05)$,Incidence of anomalies was significantly difference at groups which received VAP with control and melatonin group $(\mathrm{p}=0.0001)$, Also this incidence was difference between groups received VAP $(p<0.05)$

Incidence of omphalocele (Fig. 4) and fusion of two or more sternebrae, absence of sternebrae and malpositioning of two halves of the sternebrae in group which received sodium valproate plus melatonin $(5 \mathrm{mg}$ $\mathrm{kg}^{-1}$ ) were 8.3 and $8.3 \%$, respectively. Incidence of omphalocele and fusion of two or more sternebrae, absence of sternebrae and malpositioning of two halves of the sternebrae in group which received sodium valproate plus melatonin $\left(10 \mathrm{mg} \mathrm{kg}^{-1}\right)$ were 0 and $7.1 \%$, respectively. Mean weight and Crown Rump Length $(\mathrm{CRL})$ were significantly $(\mathrm{P}<0.001)$ decreased in group received only VAP. The means weight and length in groups that received melatonin were greater than the group received only VAP (Table 1). There were not any aborted fetuses from total groups but percentages of resorbed fetuses were 4.08, 11.76, 7.69, 4.54 and $4.65 \%$ in groups of 1-5, respectively (Table 1).

\section{DISCUSSION}

VPA is a widely used antiepileptic drug since the 1970s., leading to skeleton defects, fetal growth retardation, neural tube defects and in-uterus death (Elmazara and Nau, 1995). It is routinely used to treat epilepsy (Dalessio, 1985). However, valproic acid is also known to cross the placenta and to cause a wide spectrum of congenital anomalies, including craniofacial and skeletal defects (Lammer et al., 1987). The teratogenic effect mechanism of VAP has not been precisely clarified. Although VAP induces exencephaly in experimental animal embryos, its pathogenic mechanism is not known reported that, in the 8th day of gestation, VAP application cause growth retardation in fetuses (AL Deeb et al., 2000). In our study, growth retardation that exhibits similar findings to pregnant rat fetuses was macroscopically observed.

Numerous studies point towards the role of oxygen derived free radicals in the pathogenesis of neuaral tube defects (AL Deeb et al., 2000). Exposure of rat embryos to high concentration of oxygen during early neurulation significantly increases the incidence of neural tube defects aqnd is dependent on the capacity of the antioxidant system to combat oxygen derived free radicals (Ishibashi et al., 1997).

Several studies have reported that the maternal immune stimulation or antioxidant drugs can reduce teratogenic anomalies. Mechanisms of this effect have remained unclear (Holladay et al., 2002); however, there are indications that immunoregulatory cytokines of maternal or placental origin normalize dysregulated apoptosis or timing of cell proliferation in the fetus (Sharova et al., 2000; Hrubec et al., 2006). Vitamin E reduces fetal malformation in diabetic animals (Simon and Eriksson, 1997).

In the present study, melatonin reduced the frequency of incidence of valproate induced malformations.

Enhancing antioxidative effects can protect fetuses against anticonvulsant drugs teratogenicity (Winn and Wells, 1999). Sharova et al. (2002) showed that interferon-gamma and Freund's complete adjuvant reduced severity of the urethane - induced cleft palate in mice (Sharova et al., 2002). Torkinsky et al. (1997) reported that immune stimulation in diabetic mice, which show a high spontaneous rate of cleft palate, decreased in malformed fetuses, significantly (Torkinsky et al., 1997).

Delayed fetal development and reduced fetal sized are common sequelae of teratogenic exposures such as diabetes (Cederberg et al., 2003), ethyl carbamate (Sharova et al., 2000) and valproate (AL Deeb et al., 2000). Consistent with these previous studies, we observed decreased fetal size in the sodium valproate exposed fetuses. Maternal immune stimulation with melatonin did protect the fetus from the sodium valproate induced growth impairment, even though neural tube defects were prevented. Maternal immune stimulation reduced the incidence of ethyl carbamate 
induced cleft palate (Sharova et al., 2000) and vitamin $E$ reduced the incidence of valproate induced malformations, but had no positive effect on fetal survival or growth (Al Deeb et al., 2000).

This disparity between the reduction of fetal malformations by various interventions and lack of reductions in fetal growth impairment and mortality may be explained by differential genetic contributions by the dam and fetus to valproate teratogenicity.

Laboratory mice have been used to study the basis for VPA teratogenicity. Administration of VPA on days 8-9 of gestation results in failure of cranial neural tube closure and spina bifida, as well as limb abnormalities such as syndactyly and oligodactyly (Ehlers et al., 1992).

Menegola et al. (1998) reported that the administration of $150-300 \mathrm{mg} \mathrm{kg}^{-1}$ sodium valproate subcutaneously to pregnant mice or rats every $8 \mathrm{~h}$ during the first stages of somitogenesis is able to produce a very high incidence of malformations at the level of the axial skeleton. They observed fetal defects similar to our study including cleft palate. These anomalies were decreased by melatonin $\left(5,10 \mathrm{mg} \mathrm{kg}^{-1}\right)$, but melatonin with dose of $10 \mathrm{mg} \mathrm{kg}^{-1}$ significantly more prophylactic effect than melatonin with dose of $5 \mathrm{mg} \mathrm{kg}^{-1}$.

Melatonin or N-Acetyl-5-methoxytryptamine, the main secretary product of pineal gland, is an antioxidant (Reiter and Tan, 2003), scavenges the hydroxyl radical (Tan et al., 2002). The studies in laboratory rodents and other domestic species suggested that melatonin did not affect prenatal growth, survival, or morphology of the concepts once pregnancy had been stablished (Chan and Ng, 1994, 1995; Tigchelaar and Nalbandov, 1975). The present investigations (NTP, 1997) extend the dose range evaluated in pregnant animals and the results are consistent with earlier studies that falied to find adverse effects on prenatal growth, or gross morphological development. Jahnke et al. (1997) reported that melatonin with doses of 50 and $100 \mathrm{mg} \mathrm{kg}^{-1}$ day $^{-1}$ from gd 6 through 19 had no effect on prenatal survival, fetal body weight, or incidence of fetal malformations (Jahnke et al., 1997). The authors reported no significant differences in dam body weight or total numbers of fetuses, live fetuses, or abortions through Gd 18 (San Martin et al., 1995). In one study, melatonin with dose 5 or $10 \mathrm{mg} \mathrm{kg}^{-1}$ in mice protects against lipopolysaccaride-induced intra-uterine fetal death and growth retardation via counteracting lipopolysaccaride-induced oxidative stress (Chen et al., 2006). Omurtag et al. (2008) reported melatonin with dose $10 \mathrm{mg} \mathrm{kg}^{-1}$ day $^{-1}$ for 5 days protects against endosulfan-induced oxidative tissue damages in rats (Omurtag et al., 2008). In present study, the effect of melatonin is probably related to antioxidant activity.
In one study, melatonin with dose 5 or $10 \mathrm{mg} \mathrm{kg}^{-1}$ in mice protects against lipopolysaccaride-induced intra-uterine fetal death and growth retardation via counteracting lipopolysaccaride-induced oxidative stress (Chen et al., 2006).

Omurtag et al. (2008) reported melatonin with dose $10 \mathrm{mg} \mathrm{kg}-1 \mathrm{day}^{-1}$ for 5 days protects agaist endosulfaninduced oxidative tissue damages in rats (Omurtag et al., 2008). In present study, the effect of melatonin is probably related to antioxidant activity. In present study, the effect of levamisole is probably related to immunologic response.

\section{CONCLUSION}

In conclusion, probably VAP influences immune system that produces teratogenic effects including cleft palate and spina bifida. Effects of VAP immunosuppression are mediated indirectly by inducing oxidative stress. On the other hand, melatonin can be reduce the incidence of sodium valproate induced malformations such as cleft palate and spina bifida in fetuses of rat and had positive effect on fetal growth. Melatonin with dose of $10 \mathrm{mg} \mathrm{kg}^{-1}$ had significantly more prophylactic effect than melatonin with dose of $5 \mathrm{mg} \mathrm{kg}^{-1}$ on incidence of sodium valproate-induced skeletal malformations. This effect of melatonin may be due to its antioxidant property.

\section{ACKNOWLEDGEMENT}

The researchers wish to express their gratitude to the research council of Shahid Chamran University for their financial supports.

\section{REFERENCES}

Al Deeb, S., K. Al Moutaery, M. Arshaduddin and M. Tariq, 2000. Vitamin E decreases valproic acid induced neural tube defects in mice. Neurosci. Lett., 292: 179-82. PMID: 11018306

Cederberg, J., J.J. Picard and U.J. Eriksson, 2003. Maternal diabetes in the rat impairs the formation of neural-crest derived cranial nerve ganglia in the offspring. Diabetologia, 46: 1245-51. PMID: 12830378

Cengiz, M., A. Yuksel and M. Seven, 2000. The effects of carbamazepine and valproic acid on the erythrocyte glutathione peroxidase, superoxide dismutase and serum lipid peroxidation in epileptic children. Pharmacol. Res., 41: 423-5. PMID: 10704266 
Chan, W.Y. and T.B. Ng, 1994. Development of preimplantation, mouse embryos under the influence of pineal indoles. J. Neural Transmiss., 96: 19-29. PMID: 7531981

Chan, W.Y. and T.B. Ng, 1995. Changes induced by pineal indoles in post-implantation mouse embryos. General Pharmacol., 26: 1113-1118. DOI: 10.1016/0306-3623(94)00264-N

Chen, Y.H., D.X. Xu, J.P. Wang, H. Wang and L.Z. Wei et al., 2006. Melatonin protects against lipopolysaccharide-induced intra-uterine fetal death and growth retardation in mice. J. Pineal Res., 40: 40-47. PMID: 16313497

Clayton-Smith, J. and D. Donnai, 1995. Fetal valproate syndrome. J. Med. Genet., 32: 724-727. PMCID: PMC1051674

Cuzzocrea, S. and R.J. Reiter, 2002. Pharmacological actions of melatonin in acute and chronic inflammation. Curr. Top. Med. Chem., 2: 153-165. PMID: 11899098

Dalessio, D.J., 1985. Current concepts: Seizure disorders and pregnancy. New. Engl. J. Med., 312: 559-63. PMID: 3881676

Defoort, E.N. and L.M. Winn, 2006. Valproic acid increases conservative homologous recombination frequency and reactive oxygen species formation: a potential mechanism for valproic acid-induced neural tube defects. Mol. Pharmacol., 69: 1304-10. PMID: 16377765

Ehlers, K., H. Sturje, H.J. Merker and H. Nau, 1992. Spina bifida aperta induced by valproic acid and by all-trans-retinoic acid in the mouse: Distinct differences in morphology and periods of sensitivity. Teratology. 46: 117-130. PMID: 1440416

Elmazara, M.A. and H. Nau, 1995. Ethanol potentiates valproic acid-induced neural tube defects (NTDs) in mice due to toxicokinetic interactions. Reproduc. Toxicol., 9: 427-433. PMID: 8563186

Espinar, A., E.M., Garcia-Oliva, E.M. Isorna, A. Quesada and F.A. Prada et al., 2000. Neuroprotection by melatonin from glutamateinduced excitotoxicity during development of the cerebellum in the chick embryo. J. Pineal Res., 28: 81-88. PMID: 10709969

Finnell, R.H., 1991. Genetic differences in susceptibility to anticonvulsant drug-induced developmental defects. Pharmacol. Toxicol., 69: 223-227. PMID: 1956873

Holladay, S.D., L.V. Sharova, B.J. Smith, R.M. Gogal and D.L. Ward et al., 2000. Nonspecific stimulation of the maternal immune system. I. Effects on teratogen-induced fetal malformations. Teratology, 62: 413-419. PMID: 11811935
Holladay, S.D., L.V. Sharova, K. Punareewattana, T.C. Hrubec and R.M. Gogal et al., 2002. Maternal immune stimulation in mice decreases fetal malformations caused by teratogens. Int. Immunopharmacol., 2: 25- 332. PMID: 11091363

Hrubec, T.C., M.R. Prater, K.A. Toops and S.D. Holladay, 2006. Reduction in diabetes-induced craniofacial defects by maternal immune stimulation. Birth Defects Res. Dev. Reproduc. Toxicol., 77: 1-9. PMID: 16342200.

Ishibashi, M., S.W. Akazawa, H. Sakamaki, K. Matsumoto and H. Yamasaki et al., 1997. Oxygen induced embryopathy and the significance of glutathione dependent antioxidant system in the rat embryo during early organogenesis. Free. Radic. Biol. Med., 22: 447-54. PMID: 8981036

Jahnke, G.M., C. Myers, R. Wilson, G. Travlos and C. Price, 1997. Maternal and developmental toxicity evaluation of melatonin administered orally to pregnant Sprague-Dawley rats. Toxicol. Sci., 50: 271-279. PMID: 10478864.

Kimmel, C.A. and C. Trammekl, 1981. A rapid procedure for routine double staining of cartilage and bone in fetal and adult animals. Stain. Technology, 56: 271-273. PMID: 6171056

Koch, S., G. Losche, E. Jager-Roman, S. Jakob and D. Rating et al., 1992. Major and minor birth malformations and antiepileptic drugs. Neurology, 42: 183-88. PMID: 1574183

Konar, V., H. Kara, M. Yilmaz, A. Dayangac and F. Karatas, 2007. Effects of selenium and vitamin e, in addition to melatonin, against oxidative stress caused by cadmium in rats. Biol. Trace Element Res., 118: 131-137. PMID: 17873355

Lammer, E.J., L.E. Sever and G.P. Oakley, 1987. Teratogen update: Valproic acid. Teratology, 35: 465-473. PMID: 17873355

Lindhout, D. and J.G. Omtzigt, 1992. Pregnancy and the risk of teratogenicity. Epilepsia, 33: 541-548. . PMID: 1425493

Maertens, P., P. Dyken, W. Graf, C. Pippenger, R. Chronister and A. Shah, 1995. Free radicals, anticonvulsants and the neuronal. Am. J. Med. Genet., 57: 225-8. PMID:7668334

Menegola, E., M.L. Broccia, M. Prati and E. Giavini, 1998. Stage-dependent skeletal malformations induce by valproic acid in rat. Int. J. Biol., 42: 99102. PMID: 9496792

Mevissen, M. and U. Ebert, 1998. Anticonvulsant effects of melatonin in amygdala-kindled rats. Neurosci. Lett., 20: 13-6. PMID: 9857954 
Nomura, T., S. Hata and T. Kusafuka, 1990. Suppression of developmental anomalies by maternal macrophage in mice. J. Exp. Med., 172: 1325-1332. PMID: 2230647

NTP, 1997. Developmental Toxicity Screen for Melatonin (CAS No.73-31-4) Administrated by gavage to Sprague-Dawely (CD) Rats on Gestational days 6 through 19. NTP study No. TRP-97-001.NTP/NIEHS Contract NO.NOI-ES65405. Final Study Report, June 25: 1977.

Omurtag, G.Z., A. Tozan, A. Şehirli and G. Şener, 2008. Melatonin protects against endosulfaninduced oxidative tissue damage in rats. J. Pineal Res., 44: 432-438. PMID: 18205731

Prater, M.R., K.L. Zimmerman, D. Lee Ward and S.D. Holladay, 2004. Reduced birth defects caused by maternal immune stimulation in methylnitrosoureaexposed mice: Association with placental improvement. Birth Defects Res., 70: 862-869. PMID: 14745891

Punareewattana, K. and S.D. Holladay, 2004. Immunostimulation by complete Freund's adjuvant, granulocyte macrophage colonystimulating factor, or interferon- $\gamma$ reduces severity of diabetic embryopathy in ICR mice. Birth Defects Res. Clin. Mol. Terato., 70: 20-27. PMID: 15526292

Reiter, R.J., 1994. Melatonin as a free radical scavenger: Implications for aging and age-related diseases. Ann. Acad. Sci., 31: 1-12. PMID: 8010585

Reiter, R.J. and D.X. Tan, 2003. Melatonin: A novel protective agent against oxidative injury of the ischemic/reperfused heart. Cardiovascular Res., 58: 10-9. PMID: 12667942

Rowan, A.J., D.X. Tan, B. Poeggler, A. MenedezPalaez and L.D. Chen et al., 1997. Valproate. In: Epilepsy: A comperehensive Text Book, Engel, J. and T.A. Pedley (Eds.). Lippincott-raven Publish, Philadelphia, pp: 1599-1607. ISBN: 10: 0-78175777-5.

San Martin, M., J. Recio, E.J. Sanchez-Barcelo and M.D. Mediavilla, 1995. Melatonin inhibits mammary gland development during pregnancy. Neuroendocrinol. Lett., 17: 245-250. ISSN: 0172$780 \mathrm{X}$

Sharova, L.V., P. Sura, B.J. Smith, R.M. Jr., Gogal and A.A. Sharov et al., 2000. Nonspecific stimulation of the maternal immune system. II. Effects on gene expression in the fetus. Teratol, 62: 420-428. PMID: 11091364
Sharova, L.V., R.M. Gogal, A.A. Sharova, M.V. Chrisman and S.D. Holladay, 2002. Immune stimulation in urethane- exposed pregnant mice increase expression level of spleen leukocyte genes for TGF beta 3 GM- CSF and other cytokines that may play a role reduced chemical-induced birth defects. Int. Immunopharmacol, 10: 1477-89. PMID: 12400877

Simon, C.M. and U.J. Eriksson, 1997. Vitamin E decreases the occurrence of malformations in the offspring of diabetic rats. Diabetes, 46: 1054-61. PMID: 9166679

Srivastava, A.K., S.K. Gupta, S. Jain and Y.K. Gupta, 2002. Effect of melatonin and phenytoin on an intracortical ferric chloride model of posttraumatic seizures in rats. Methods Find. Exp. Clin. Pharmacol., 24: 145. PMID: 12087876

Syska, E., R. Schmidt and J. Schubert, 2004. The time of palatal fusion in mice: A factor of strain susceptibility to teratogens. J. Craniomaxillofac. Surg., 32: 2-4. PMID: 14729041

Tan, D.X., R.J. Reiter, L.C. Manchester, M.T. Yan and M. El-Sawi et al., 2002. Chemical and physical properties and potential mechanisms: Melatonin as a broad spectrum antioxidant and free radical scavenger. Curr. Topics Med. Chem., 2: 181-197. PMID: 11899100

Tigchelaar, P. and A.V. Nalbandov, 1975. The Effect of the Pineal Gland on Ovulation and Pregnancy in the Rat. Biol. Reprod, 13: 461-469. PMID: 1222203

Torkinsky, A., V. Tolder, S. Savion, J. Shepshelovich and H. Orenstein et al., 1997. Immunostimulation increases the resistance of mouse embryos to the teratogenic effects of diabetic mellitus. Diabetologica, 40: 635-640. PMID: 9222641

Wang, J.F, J.E. Azzam and LT. Young, 2003. Valproate inhibits oxidative damage to lipid and protein in primary cultured rat cerebrocortical cells. Neuroscience, 116: 486-489. PMID: 12559103

Winn, L.M. and P.G. Wells, 1999. Maternal administration of superoxide dismutase and catalase in phenytoin teratogenicity. Free Radic. Biol. Med., 26: 266-274. PMID: 9895216

Zhang, H., G.L. Squadrito and W.A. Pryor, 1998. The reaction of melatonin with peroxynitrite: Formation of melatonin radical cation and absence of stable nitrated products. Biochem. Biophys. Res. Commun., 251: 83-87. PMID: 9790911 